\title{
Collective relaxation of protein protons at very low magnetic field: a new
}

\author{
window on protein dynamics and aggregation
}

Claudio Luchinat* and Giacomo Parigi

\section{Supporting information}

Magnetic Resonance Center and Department of Agricultural Biotechnology, University of Florence,

Via Maragliano 75/77, 50144 Florence, Italy

email: luchinat@cerm.unifi.it

FAX: +39-055-4574253 


\section{CORMA calculations for increasing magnetic fields}

In order to estimate spin diffusion effects, CORMA calculations were performed for different magnetic fields (from 0.01 to $500 \mathrm{MHz}$ ) to obtain the relaxation rate distribution for lysozyme $\mathrm{CH}$ and $\mathrm{CH}_{2}$ protons in the assumption of no internal motion. Two peaks in the relaxation rate distribution are clearly visible up to $15 \mathrm{MHz}$, with almost constant ratio between the relative relaxation rate values. At $45 \mathrm{MHz}$ the distribution is more broad and the ratio between the relaxation rate values at the two peaks is reduced. At $100 \mathrm{MHz}$ the two peaks are no longer distinguishable, and at $200 \mathrm{MHz}$ they are merged into a single peak.

Fig. S1. Relaxation rate distribution calculated for lysozyme $\mathrm{CH}$ and $\mathrm{CH}_{2}$ protons at $0.1,15,45,100$ and $200 \mathrm{MHz}$.
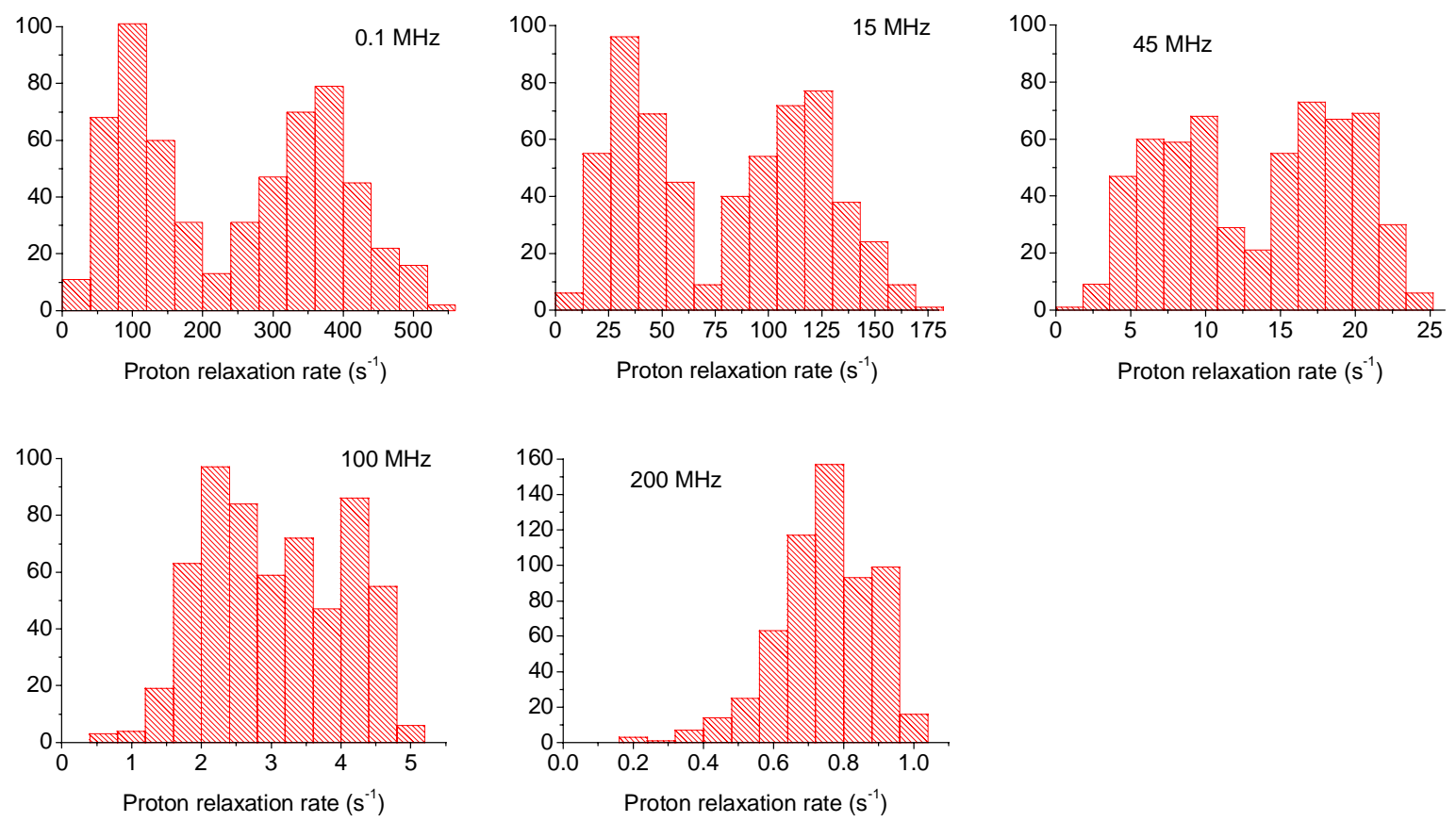


\section{Best fit of simulated relaxation dispersion data}

$J(\omega, \tau)$ in Eq. (5) is usually approximated to a Lorentzian function or to a sum of Lorentzian functions: ${ }^{1}$

$$
J(\omega, \tau)=\frac{\sum_{i} c_{i} \frac{\tau}{1+\left(n_{i} \omega \tau\right)^{2}}}{\sum_{i} c_{i}} .
$$

$J_{1}(\omega, \tau)$ (see Eq. 6) is used for ${ }^{2} \mathrm{H}$ and ${ }^{17} \mathrm{O}$ relaxation dispersions; the equation is appropriate also for quadrupolar relaxation, which is the dominant relaxation mechanism for these nuclei in slowly tumbling systems. A combination of $J_{1}(\omega, \tau)$ and $J_{2}(\omega, \tau)$ (see Eq. 7) is often used for ${ }^{1} \mathrm{H}$ relaxation dispersions; ${ }^{2-4}$ in this case $J_{1}(\omega, \tau)$ accounts for intramolecular ${ }^{1} \mathrm{H}_{-}{ }^{1} \mathrm{H}$ dipolar coupling of the water molecule, and $J_{2}(\omega, \tau)$ for its intermolecular coupling with protein protons as well as for the relaxation of exchangeable protein protons themselves. In the present direct approach to protein proton relaxation dispersion, it would seem that $J_{2}(\omega, \tau)$ should be used, because there are no two equivalent protons in a protein, besides the methyl protons. However, the presence of the non-dispersive term $0.1 \tau$ in $J_{2}(\omega, \tau)$ immediately suggests that this function is inappropriate to describe the experimental data. In fact, it is clear that the experimentally obtained profiles decay basically to zero at high fields ${ }^{5}$ (see also Fig. 5). To understand why this is so, we recollect that, being a low-resolution technique, relaxometry always excites, and measures the magnetization decay of, all protons of the sample. In proteins, that rotate slowly and where each proton simultaneously interacts with several other protons, the so-called spindiffusion effects become operative, and $R_{1}$ tends to zero at high field rather than to one tenth of its low field value as predicted by $J_{2}(\omega, \tau)$.

Protein proton relaxation dispersion profiles were calculated with CORMA. In CORMA all spectral densities for all not-methyl protons are given by $J_{2}(\omega, \tau)$ terms but the signal decays are the result of a diagonalization of the whole matrix. Actually, the profiles do decay to zero with increasing field. 
Therefore, the system behaves as if all protons were "equivalent", as they would be if $J_{1}(\omega, \tau)$ instead of $J_{2}(\omega, \tau)$ were used in Eq. 5. Indeed, a fit of simulated profiles for single protein protons indicates that either $J_{1}(\omega, \tau), J_{2}(\omega, \tau)$ or a combination of them is inadequate to reproduce the dispersion (see Fig. S2), and, in any case, a different combination would result for the different protons of the protein. If $J_{1}(\omega, \tau)$ is used, for instance, the best fit values of $\tau$ obtained for the 4 protons $\mathrm{H}^{\alpha} 56, \mathrm{H}^{\mathrm{N}} 58, \mathrm{H}^{\gamma 1} 78$ and $\mathrm{H}^{\delta 1}$ 116 are $6.6,8.6,8.4$ and 10.3 , respectively, instead of $9.0 \mathrm{~ns}$, which is the value imposed in the CORMA calculations. The best-fit squared dipolar interaction energies $\left(12.1,21.0,31.2\right.$ and $53.1 \times 10^{9}$ $\left.\mathrm{s}^{-2}\right)$ are also in disagreement with the values calculated with CORMA $\left(15.9,20.5,29.5\right.$ and $57.8 \times 10^{9}$ $\left.\mathrm{s}^{-2}\right)$. If $J_{2}(\omega, \tau)$ is used, even without the non-dispersive term, the best fit values of $\tau$ for the same 4 protons are 7.4, 9.6, 9.4 and $11.6 \mathrm{~ns}$, respectively, and the squared dipolar interaction energies are 10.9, $18.9,28.1$ and $47.7 \times 10^{9} \mathrm{~s}^{-2}$.

On the other end, if the fit is performed for the collective protein proton relaxation profile, i.e., for the average of the relaxation rates of all protons, using $J_{1}(\omega, \tau)$ in Eq. 1, it turns out to be very good (see Fig. S3), with a reduced $\chi^{2}$ value of 0.00002 compared with $\chi^{2}$ values up to 0.0051 from the fits in Fig. S2, and with best-fit values of $\tau(9.02 \pm 0.04 \mathrm{~ns})$ and $\left\langle E^{2}\right\rangle\left(27.2 \pm 0.1 \times 10^{9} \mathrm{~s}^{-2}\right)$. The latter values are basically coincident with those imposed to the CORMA calculations $(9.0 \mathrm{~ns})$ and with the average squared dipolar energy calculated with CORMA $\left(27.1 \times 10^{9} \mathrm{~s}^{-2}\right)$, respectively. On the contrary, the fit performed using $J_{2}(\omega, \tau)$ in Eq. 1, even without the non-dispersive term, provides an incorrect $\tau$ value of $10.1 \pm 0.1 \mathrm{~ns}$. 
Figure S2. Best fit of the relaxation rate dispersion profiles calculated with CORMA (symbols) for protons $\mathrm{H}^{\alpha} 56, \mathrm{H}^{\mathrm{N}} 58, \mathrm{H}^{\gamma 1} 78$ and $\mathrm{H}^{\delta 1} 116$, performed using the spectral density function $J_{1}(\omega, \tau)(\mathrm{A})$ or $J_{2}(\omega, \tau)$ without the non-dispersive term (B). Calculated relaxation rate dispersion profiles using $J_{1}(\omega, \tau)$ (C) or $J_{2}(\omega, \tau)$ without the non-dispersive term (D) and the same $\tau$ and $\left\langle E_{i}^{2}\right\rangle$ values used in CORMA.
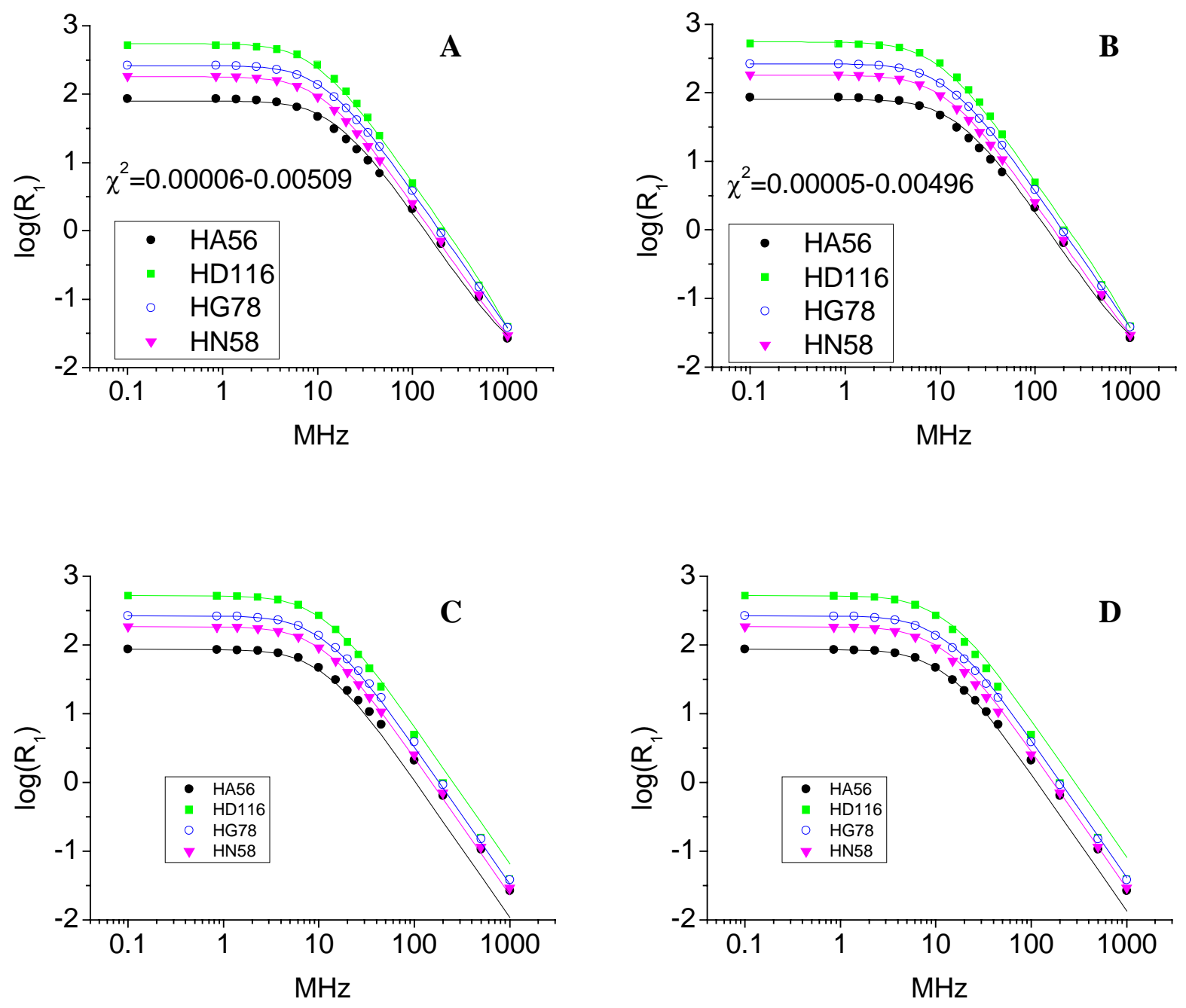
Figure S3. Fit of the collective protein proton relaxation rates calculated from data simulated with CORMA as a function of magnetic field, performed using the spectral density function $J_{1}(\omega, \tau)$.

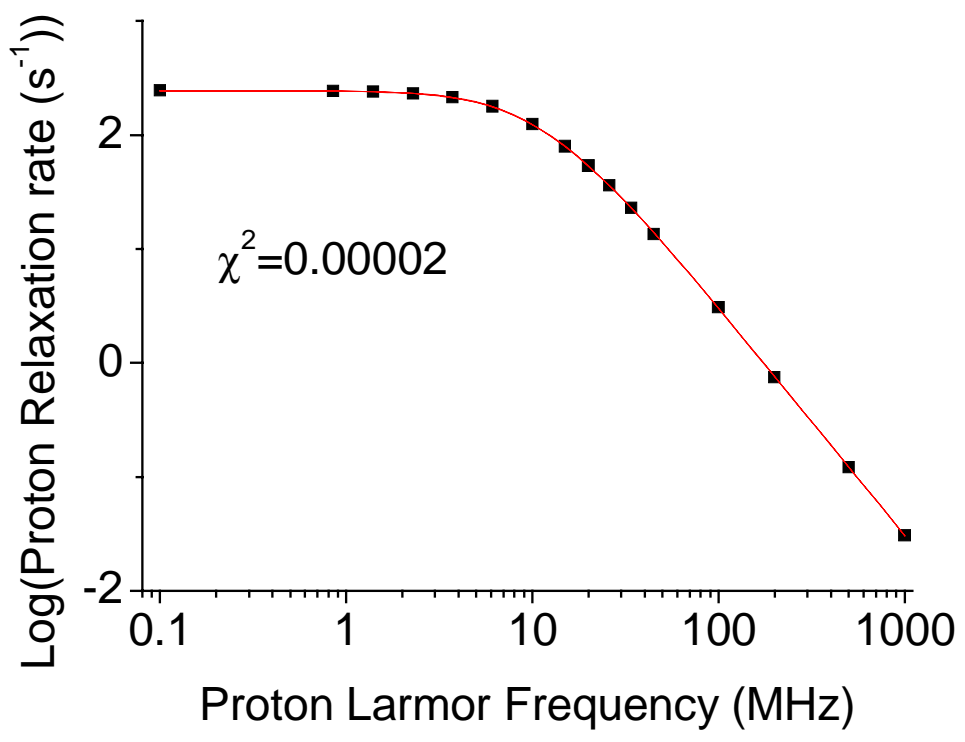




\section{Equations used in the fit of the magnetization decay/recovery}

Equation used for the fit of the magnetization decay:

$$
\begin{aligned}
& \mathrm{y}=\mathrm{P} 1+\mathrm{P} 2 *\left(0.0076^{*} \exp \left(-\mathrm{P} 3 * \mathrm{x}^{*} 0.11^{\wedge}(1+\mathrm{P} 4)\right)+0.0079 * \exp \left(-\mathrm{P} 3 * \mathrm{x}^{*} 0.13^{\wedge}(1+\mathrm{P} 4)\right)+0.0051^{*} \exp (-\right. \\
& \left.\mathrm{P}^{*} \mathrm{x}^{*} 0.16^{\wedge}(1+\mathrm{P} 4)\right)+0.0098^{*} \exp \left(-\mathrm{P} 3^{*} \mathrm{x}^{*} 0.19^{\wedge}(1+\mathrm{P} 4)\right)+0.0166^{*} \exp \left(-\mathrm{P} 3 * \mathrm{x}^{*} 0.229^{\wedge}\right. \\
& (1+\mathrm{P} 4))+0.0234^{*} \exp \left(-\mathrm{P} 3 * \mathrm{x}^{*} 0.275^{\wedge}(1+\mathrm{P} 4)\right)+0.0267^{*} \exp \left(-\mathrm{P} 3 * \mathrm{x}^{*} 0.331^{\wedge}(1+\mathrm{P} 4)\right)+0.0316^{*} \exp (- \\
& \left.\mathrm{P} 3 * \mathrm{x}^{*} 0.398^{\wedge}(1+\mathrm{P} 4)\right)+0.0532^{*} \exp \left(-\mathrm{P} 3 * \mathrm{x}^{*} 0.479^{\wedge}(1+\mathrm{P} 4)\right)+0.0673^{*} \exp \left(-\mathrm{P} 3 * \mathrm{x}^{*} 0.575^{\wedge}\right. \\
& (1+\mathrm{P} 4))+0.0784 * \exp \left(-\mathrm{P} 3 * \mathrm{x} * 0.692^{\wedge}(1+\mathrm{P} 4)\right)+0.102 * \exp \left(-\mathrm{P} 3 * \mathrm{x} * 0.832^{\wedge}(1+\mathrm{P} 4)\right)+0.1223 * \exp (-\mathrm{P} 3 * \mathrm{x} \\
& \text { *1. })+0.0881^{*} \exp \left(-\mathrm{P} 3 * \mathrm{x}^{*} 1.202^{\wedge}(1+\mathrm{P} 4)\right)+0.0566^{*} \exp \left(-\mathrm{P} 3 * \mathrm{x}^{*} 1.445^{\wedge}(1+\mathrm{P} 4)\right)+0.0588^{*} \exp \left(-\mathrm{P} 3^{*} \mathrm{x}^{*} 1.74^{\wedge}\right. \\
& (1+\mathrm{P} 4))+0.0751^{*} \exp \left(-\mathrm{P} 3 * \mathrm{x}^{*} 2.09^{\wedge}(1+\mathrm{P} 4)\right)+0.0849 * \exp \left(-\mathrm{P} 3 * \mathrm{x}^{*} 2.512^{\wedge}(1+\mathrm{P} 4)\right)+0.0575^{*} \exp (- \\
& \left.\left.\mathrm{P} 3 * \mathrm{x}^{*} 3.02^{\wedge}(1+\mathrm{P} 4)\right)+0.0208^{*} \exp \left(-\mathrm{P} 3 * \mathrm{x}^{*} 3.63^{\wedge}(1+\mathrm{P} 4)\right)+0.0069 * \exp \left(-\mathrm{P} 3 * \mathrm{x}^{*} 4.37^{\wedge}(1+\mathrm{P} 4)\right)\right)
\end{aligned}
$$

$\mathrm{P} 1, \mathrm{P} 2, \mathrm{P} 3$ and $\mathrm{P} 4$ are the fit parameters $\gamma, \beta, R_{A}$ and $\varepsilon$, respectively (see Eq. (3)); $\mathrm{x}$ is the time and $\mathrm{y}$ is the magnetization value. The difference between the calculated and experimental magnetization values is minimized.

The relaxation rate is calculated according to the following equation:

$$
\begin{aligned}
& 0.0076^{*} \mathrm{P} 3 * 0.11^{\wedge}(1+\mathrm{P} 4)+0.0079 * \mathrm{P} 3 * 0.13^{\wedge}(1+\mathrm{P} 4)+0.0051^{*} \mathrm{P} 3 * 0.16^{\wedge}(1+\mathrm{P} 4)+0.0098^{*} \mathrm{P} 3^{*} 0.19^{\wedge} \\
& (1+\mathrm{P} 4)+0.0166^{*} \mathrm{P} 3 * 0.229^{\wedge}(1+\mathrm{P} 4)+0.0234 * \mathrm{P} 3 * 0.275^{\wedge}(1+\mathrm{P} 4)+0.0267 * \mathrm{P} 3 * 0.331^{\wedge} \\
& (1+\mathrm{P} 4)+0.0316^{*} \mathrm{P} 3 * 0.398^{\wedge}(1+\mathrm{P} 4)+0.0532 * \mathrm{P} 3 * 0.479^{\wedge}(1+\mathrm{P} 4)+0.0673 * \mathrm{P} 3 * 0.575^{\wedge} \\
& (1+\mathrm{P} 4)+0.0784^{*} \mathrm{P} 3 * 0.692^{\wedge}(1+\mathrm{P} 4)+0.102^{*} \mathrm{P} 3 * 0.832^{\wedge}(1+\mathrm{P} 4)+0.1223^{*} \mathrm{P} 3 * 1 .+0.0881 * \mathrm{P} 3 * 1.202^{\wedge} \\
& (1+\mathrm{P} 4)+0.0566^{*} \mathrm{P} 3 * 1.445^{\wedge}(1+\mathrm{P} 4)+0.0588^{*} \mathrm{P} 3 * 1.74^{\wedge}(1+\mathrm{P} 4)+0.0751^{*} \mathrm{P} 3 * 2.09^{\wedge} \\
& (1+\mathrm{P} 4)+0.0849 * \mathrm{P} 3 * 2.512^{\wedge}(1+\mathrm{P} 4)+0.0575^{*} \mathrm{P} 3 * 3.02^{\wedge}(1+\mathrm{P} 4)+0.0208 * \mathrm{P} 3 * 3.63^{\wedge}(1+\mathrm{P} 4) \\
& +0.0069^{*} \mathrm{P} 3 * 4.37^{\wedge}(1+\mathrm{P} 4)
\end{aligned}
$$


The equation used for the fit of the magnetization recovery is the same used to fit the magnetization decay, with $1-\exp (\ldots)$ in the place of $\exp (\ldots)$. 


\section{Tables of best fit collective protein proton relaxation rates}

Table S1. Collective protein proton relaxation rates obtained for the lysozyme sample

\begin{tabular}{|c|c|c|}
\hline $\mathrm{MHz}$ & Rate $\left(s^{-1}\right)$ & \pm Error $\left(\mathrm{s}^{-1}\right)$ \\
\hline 45 & 12.3 & 0.1 \\
\hline 34 & 18.2 & 0.1 \\
\hline 26 & 27.1 & 0.3 \\
\hline 20 & 42.1 & 0.8 \\
\hline 15 & 56. & 1. \\
\hline 10 & 97. & 1. \\
\hline 6.1 & 130. & 1. \\
\hline 3.73 & 153. & 2. \\
\hline 2.28 & 161. & 2. \\
\hline 1.39 & 171. & 2. \\
\hline 0.85 & 171. & 2. \\
\hline 0.52 & 173. & 2. \\
\hline 0.32 & 175 & 3. \\
\hline 0.19 & 180. & 2. \\
\hline 0.12 & 177. & 2. \\
\hline 0.07 & 179. & 2 \\
\hline 0.04 & 178. & 2. \\
\hline 0.027 & 179. & 2. \\
\hline 0.016 & 179. & 2. \\
\hline 0.01 & 186. & 2. \\
\hline
\end{tabular}


Table S2. Collective protein proton relaxation rates obtained for the $0.94 \mathrm{mM}$ HSA sample

$$
\mathrm{MHz} \text { Rate }\left(\mathrm{s}^{-1}\right) \quad \pm \text { Error }\left(\mathrm{s}^{-1}\right)
$$

$45 \quad 4.7 \quad 0.1$

$36 \quad 5.8 \quad 0.1$

$29 \quad 7.6 \quad 0.1$

$\begin{array}{lll}23 & 10.3 & 0.2\end{array}$

$19 \quad 13.5 \quad 0.3$

$\begin{array}{lll}15 & 18.8 & 0.5\end{array}$

$\begin{array}{lll}10 & 42.0 & 0.5\end{array}$

$6.193 . \quad 1$.

3.73192.

$2.28 \quad 386$.

$1.396 .8 \times 10^{2} \quad 0.1 \times 10^{2}$.

$0.85 \quad 1.02 \times 10^{3} \quad 0.02 \times 10^{3}$

$0.52 \quad 1.31 \times 10^{3} \quad 0.04 \times 10^{3}$

$0.32 \quad 1.44 \times 10^{3} \quad 0.04 \times 10^{3}$

$0.19 \quad 1.52 \times 10^{3} \quad 0.05 \times 10^{3}$

$0.12 \quad 1.51 \times 10^{3} \quad 0.05 \times 10^{3}$

$0.07 \quad 1.57 \times 10^{3} \quad 0.05 \times 10^{3}$

$0.04 \quad 1.57 \times 10^{3} \quad 0.05 \times 10^{3}$

$0.03 \quad 1.62 \times 10^{3} \quad 0.05 \times 10^{3}$

$0.02 \quad 1.59 \times 10^{3} \quad 0.05 \times 10^{3}$

$0.01 \quad 1.55 \times 10^{3} \quad 0.05 \times 10^{3}$ 
Table S3. Collective protein proton relaxation rates obtained for the $1.8 \mathrm{mM}$ HSA sample $\mathrm{MHz} \quad$ Rate $\left(\mathrm{s}^{-1}\right) \quad \pm$ Error $\left(\mathrm{s}^{-1}\right)$

$35 \quad 4.27 \quad 0.05$

$28.3 \quad 5.35 \quad 0.07$

$22.9 \quad 7.0 \quad 0.1$

$\begin{array}{lll}18.5 & 9.1 & 0.2\end{array}$

$\begin{array}{lll}10 & 29.1 & 0.4\end{array}$

$\begin{array}{lll}6.1 & 64.6 & 0.9\end{array}$

$3.73 \quad 141 \quad 2$

$\begin{array}{lll}2.28 & 300 \quad 5\end{array}$

$1.395 .9 \times 10^{2} \quad 0.1 \times 10^{2}$

$0.859 .7 \times 10^{2} \quad 0.2 \times 10^{2}$

$0.52 \quad 1.43 \times 10^{3} \quad 0.04 \times 10^{3}$

$0.32 \quad 1.72 \times 10^{3} \quad 0.05 \times 10^{3}$

$0.19 \quad 1.80 \times 10^{3} \quad 0.06 \times 10^{3}$

$0.12 \quad 1.93 \times 10^{3} \quad 0.06 \times 10^{3}$

$0.072 \quad 1.97 \times 10^{3} \quad 0.07 \times 10^{3}$

$0.0442 .01 \times 10^{3} \quad 0.07 \times 10^{3}$

$0.027 \quad 2.01 \times 10^{3} \quad 0.07 \times 10^{3}$

$0.0161 .95 \times 10^{3} \quad 0.07 \times 10^{3}$ 


\section{References}

(1) Bertini, I.; Fragai, M.; Luchinat, C.; Parigi, G. Magn.Reson.Chem. 2000, 38, 543-550.

(2) Banci, L.; Berners-Price, S.; Bertini, I.; Clementi, V.; Luchinat, C.; Spyroulias, G. A.; Turano, P. Mol.Phys. 1998, 95, 797-808.

(3) Venu, K.; Denisov, V. P.; Halle, B. J.Am.Chem.Soc. 1997, 119, 3122-3134.

(4) Halle, B.; Denisov, V. P.; Venu, K. Biological Magnetic Resonance 1999, 17, 419-483.

(5) Bertini, I.; Gupta, Y. K.; Luchinat, C.; Parigi, G.; Schlörb, C.; Schwalbe, H. Angew.Chem.Int.Ed. 2005, 44, 2-4. 